\title{
Case Report \\ Compressive Optic Neuropathy Caused by Orbital Non-Hodgkin's Lymphoma
}

\author{
Mohammed M. Ziaei and Hadi Ziaei \\ Department of Ophthalmology, Central Middlesex Hospital, Acton Lane, London NW10 7NS, UK \\ Correspondence should be addressed to Mohammed M. Ziaei, m.ziaei@doctors.org.uk
}

Received 28 November 2011; Accepted 18 January 2012

Academic Editors: A. A. Bialasiewicz and D. S. Boyer

Copyright (๑) 2012 M. M. Ziaei and H. Ziaei. This is an open access article distributed under the Creative Commons Attribution License, which permits unrestricted use, distribution, and reproduction in any medium, provided the original work is properly cited.

Purpose. To present a unique case of Non-Hodgkin's-Lymphoma- (NHL) associated compressive optic neuropathy. Method. An 89-year-old male presenting with acute unilateral visual loss and headache. Results. Patient was initially diagnosed with occult giant cell arteritis; however after visual acuity deteriorated despite normal inflammatory markers, an urgent MRI scan revealed an extensive paranasal sinus mass compressing the optic nerve. Conclusion. Paranasal sinus malignancies occasionally present to the ophthalmologist with signs of optic nerve compression and must be included in the differential diagnosis of acute visual loss.

\section{Introduction}

Paranasal sinus lymphoma is an uncommon malignancy which poses significant diagnostic challenges. Often difficult to diagnose, paranasal mass lesions can potentially cause visual loss by compressing the optic nerve, but only a few such cases have ever been reported in the literature [1-5].

\section{Case Presentation}

An 89-year-old male was seen in the eye clinic with a oneweek history of painless visual loss in the left eye along with a recent onset of left-sided headache and malaise. A thorough systemic history failed to reveal any other symptoms. His past ocular history included bilateral pseudophakia whilst he was on medication for hypertension, asthma, and hiatus hernia. Examination revealed a VA of 6/150 (1.36 LOGMAR) in the left eye with reduced colour vision (no colour plates correctly identified on the Ishihara chart). A left relative afferent pupillary defect was detected but neuroophthalmological examination was otherwise unremarkable. Anterior segment examination was normal with clear media and well-centred intraocular lenses. Right fundal examination was unremarkable whilst the left fundus exam revealed pallor of the left optic disc (Figure 1). Fundus fluorescein angiography and macular optical coherence tomography were unremarkable. Left temporal and frontal tenderness was also noted but lymphadenopathy could not be elicited. Blood tests revealed a normal full blood count, electrolytes, ESR (19 mm/hour), and CRP (2.0 mg/L).

A provisional diagnosis of occult giant cell arteritis was made and the patient was started on $1 \mathrm{mg} / \mathrm{kg}$ of oral prednisolone. A temporal artery biopsy arranged 5 days later failed to demonstrate any arteritic or granulomatous changes. At this stage a CT of head and orbit was ordered which was reported as showing no orbital or intracranial abnormalities.

The patient initially responded well to the corticosteroid treatment with the VA improving to 6/19 (0.5 LOGMAR) a week later. The patient was then monitored and the dose of steroid tapered but the established diagnosis was questioned when the visual acuity declined to 6/60 (1.02 LOGMAR) and the optic disc pallor progressed despite normal inflammatory markers. At this stage a progressive optic neuropathy was suspected and an urgent MRI scan organised which revealed a large soft tissue lesion within the left paranasal sinuses centred on the ethmoidal air cells with narrowing of the medial wall of the orbit causing optic nerve distortion and compression (Figure 2).

An urgent biopsy was arranged with the ENT team which showed aggressive diffuse large B-cell NHL. The patient was 


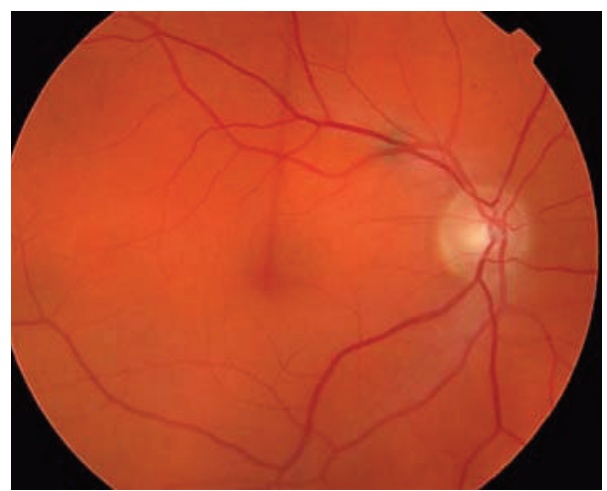

(a)

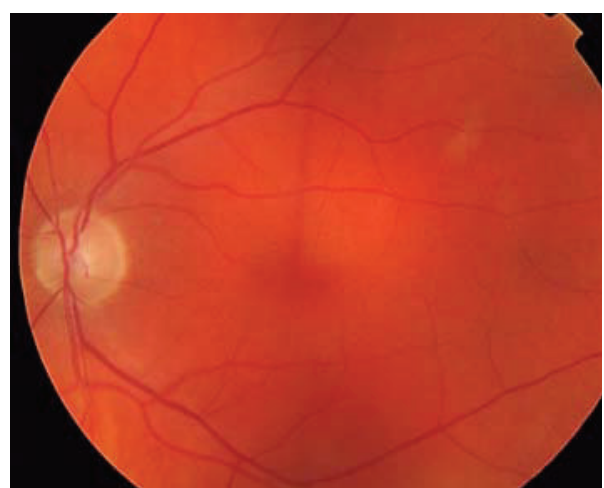

(b)

FIGURE 1: Fundal examination reveals a pale left optic nerve.

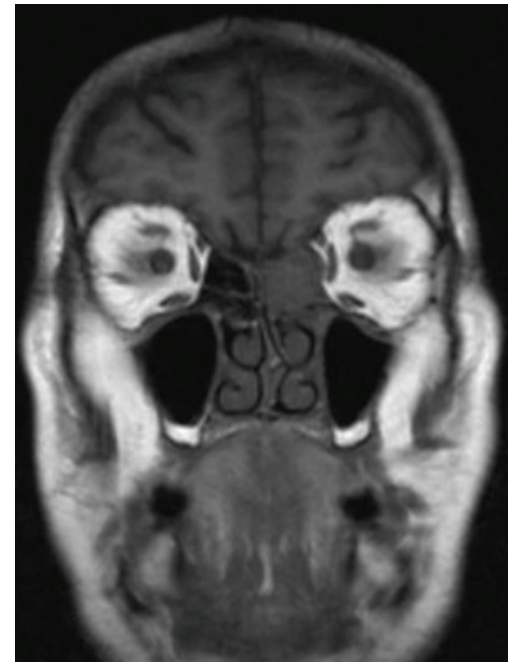

(a)

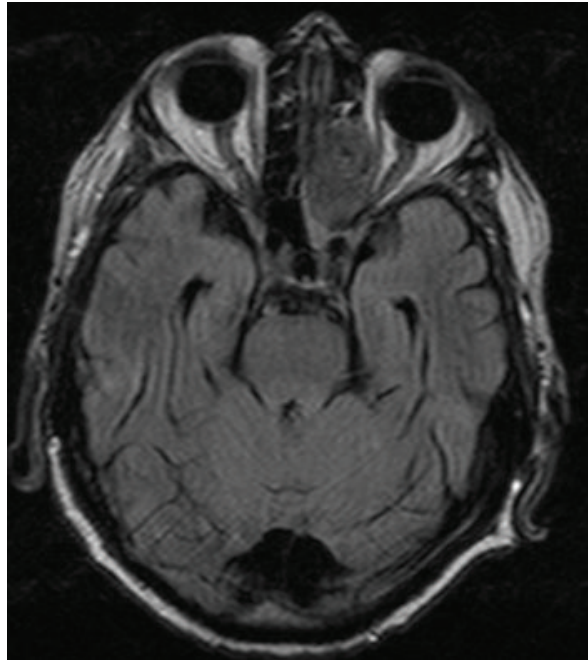

(b)

FIGURE 2: MRI scan shows an abnormal soft tissue lesion within the left paranasal sinuses centered on the ethmoid air cells. Note the distortion of the medial wall of the orbit and narrowing of the orbital apex causing distortion and compression of the left optic nerve.

referred to a tertiary centre for treatment and has done well with 3 courses of CHOP (cyclophosphamide, doxorubicin, vincristine, and prednisolone) chemotherapy and involved field radiotherapy.

\section{Discussion}

Lymphomas represent a group of malignant neoplasms of lymphoreticular origin which are divided into Hodgkin's disease and NHL [6]. The majority of head and neck NHLs originate from extranodular sites such as lymphoid tissue of Waldeyer's tonsillar ring [7] whilst lymphomas of the nasal cavity and paranasal sinuses are rare, accounting for only $0.17 \%$ of all lymphomas [8]. Patients are usually elderly males often with locally advanced tumours [9]. The majority of sinonasal lymphomas are of a diffuse B-cell origin and are classified as stage E1 according to the Ann Arbor system $[10,11]$.
In one case series the symptoms reported by patients with paranasal sinus lymphoma were nasal obstruction (100\%), epistaxis (58\%), headaches resistant to analgesia (50\%), facial swelling (50\%), palatal lesion (42\%), and diplopia (17\%) [9].

Orbital invasion is a common manifestation of sinus malignancy with frequent presenting signs and symptoms include proptosis, dystopia, visual loss, lid oedema, extraocular movement limitation, diplopia, conjunctival chemosis/ injection, eye pain, and photophobia [1].

Treatment options for sinonasal lymphomas include radiation and chemotherapy with some studies showing preference with radiation alone in early disease stages [12, 13], whilst others propose a combined treatment regimen that offers an improved disease-free survival and overall survival rates [14].

Despite treatment paranasal sinus lymphoma carries a poor prognosis (50\% 5-year survival rate) often due to a delay in diagnosis as tumors in this area are often asymptomatic 
initially and are at an advanced stage at the time of diagnosis [1].

Ophthalmological symptoms and signs often occur early in its natural history as a result of the close proximity of the orbital structures to the paranasal sinuses. The ophthalmologist's role therefore is one of upmost importance in recognising the clinical red flags associated with ocular manifestations of this malignancy and in ensuring a multidisciplinary approach in patient investigation, management, and followup.

\section{Conflict of Interests}

The authors report no conflicts of interest. We warrant that this paper is original and has not been in part or in whole simultaneously submitted to or published in another journal.

\section{References}

[1] L. N. Johnson, R. S. Hepler, R. D. Yee, and U. Batzdorf, "Sphenoid sinus mucocele (anterior clinoid variant) mimicking diabetic ophthalmoplegia and retrobulbar neuritis," American Journal of Ophthalmology, vol. 102, no. 1, pp. 111-115, 1986.

[2] I. M. Dunya, G. T. Frangieh, C. B. Heilman, M. R. Miranda, L. I. Rand, and T. R. Hedges, "Anterior clinoid mucocele masquerading as retrobulbar neuritis," Ophthalmic Plastic and Reconstructive Surgery, vol. 12, no. 3, pp. 171-173, 1996.

[3] P. I. Chou, Y. S. Chang, S. E. Feldon, and J. T. Chen, "Optic canal mucocoele from anterior clinoid pneumatisation," British Journal of Ophthalmology, vol. 83, no. 11, pp. 1306-1307, 1999.

[4] J. R. Coppeto, M. L. R. Monteiro, and D. B. Cannarozzi, "Optic neuropathy associated with chronic lymphomatous meningitis," Journal of Clinical Neuro-Ophthalmology, vol. 8, no. 1, pp. 39-45, 1988.

[5] T. Hayashi, K. Watanabe, Y. Tsuura et al., "Sight-threatening optic neuropathy is associated with paranasal lymphoma," Clinical Ophthalmology, vol. 4, pp. 143-146, 2010.

[6] I. Shohat, M. Berkowicz, S. Dori et al., "Primary nonhodgkin's lymphoma of the sinonasal tract," Oral Surgery, Oral Medicine, Oral Pathology, Oral Radiology, and Endodontics, vol. 97, no. 3, pp. 328-331, 2004.

[7] F. L. McNelis and V. T. Pai, "Malignant lymphoma of head and neck," Laryngoscope, vol. 79, no. 6, pp. 1076-1086, 1969.

[8] M. D. Logsdon, C. S. Ha, V. S. Kavadi, F. Cabanillas, M. A. Hess, and J. D. Cox, "Lymphoma of the nasal cavity and paranasal sinuses: improved outcome and altered prognostic factors with combined modality therapy," Cancer, vol. 80, no. 3, pp. 477-488, 1997.

[9] T. Chalastras, A. Elefteriadou, J. Giotakis et al., "Nonhodgkin's lymphoma of nasal cavity and paranasal sinuses. A clinicopathological and immunohistochemical study," Acta Otorhinolaryngologica Italica, vol. 27, no. 1, pp. 6-9, 2007.

[10] C. Hatta, H. Ogasawara, J. Okita, A. Kubota, M. Ishida, and M. Sakagami, "Non-hodgkin's malignant lymphoma of the sinonasal tract-treatment outcome for 53 patients according to REAL classification," Auris Nasus Larynx, vol. 28, no. 1, pp. 55-60, 2001.

[11] H. F. Frierson, S. E. Mills, and D. J. Innes, "Non-hodgkin's lymphomas of the sinonasal region: histologic subtypes and their clinicopathologic features," American Journal of Clinical Pathology, vol. 81, no. 6, pp. 721-727, 1984.

[12] N. Shikama, I. Izuno, M. Oguchi et al., "Clinical stage IE primary lymphoma of the nasal cavity: radiation therapy and chemotherapy," Radiology, vol. 204, no. 2, pp. 467-470, 1997.

[13] G. M. Proulx, I. Caudra-Garcia, J. Ferry et al., "Lymphoma of the nasal cavity and paranasal sinuses: treatment and outcome of early-stage disease," American Journal of Clinical Oncology, vol. 26, no. 1, pp. 6-11, 2003.

[14] J. Hausdorff, E. Davis, G. Long et al., "Non-hodgkin's lymphoma of the paranasal sinuses: clinical and pathological features, and response to combined-modality therapy," Cancer Journal from Scientific American, vol. 3, no. 5, pp. 303-311, 1997. 


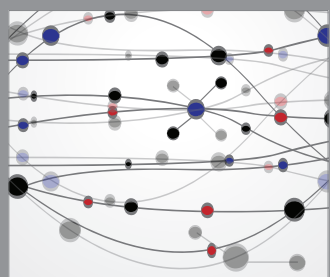

The Scientific World Journal
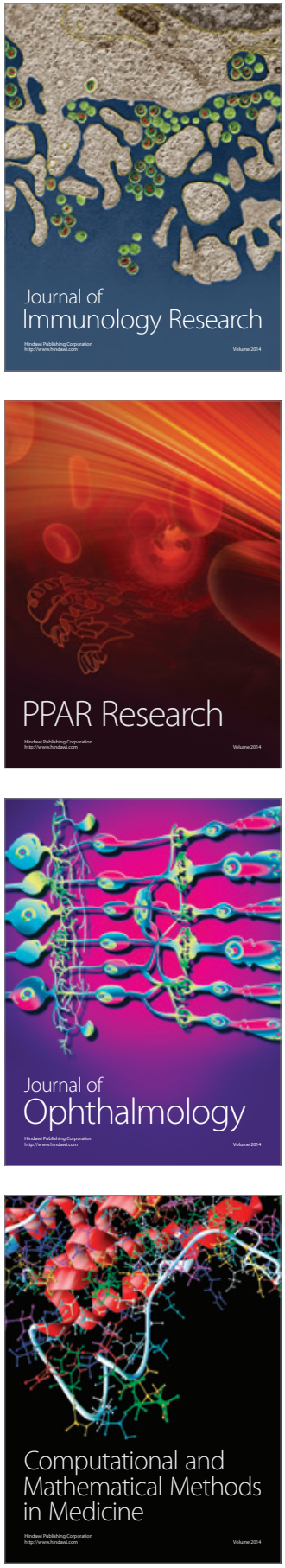

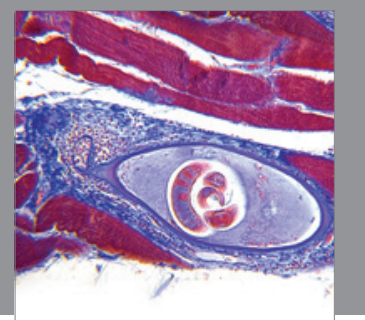

Gastroenterology

Research and Practice
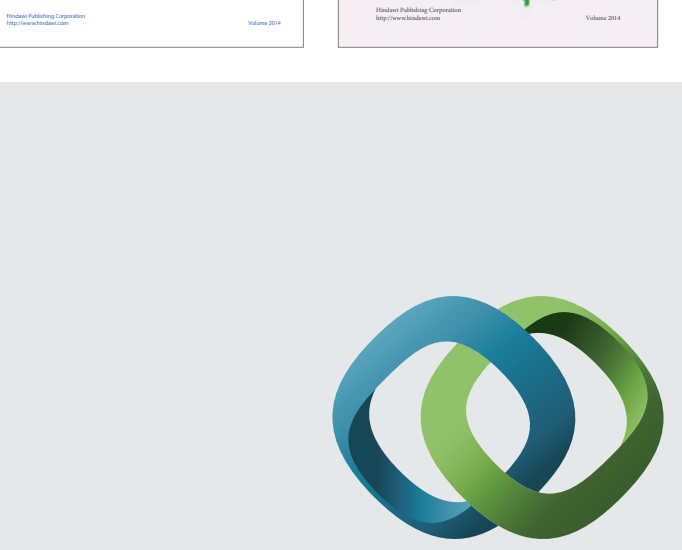

\section{Hindawi}

Submit your manuscripts at

http://www.hindawi.com
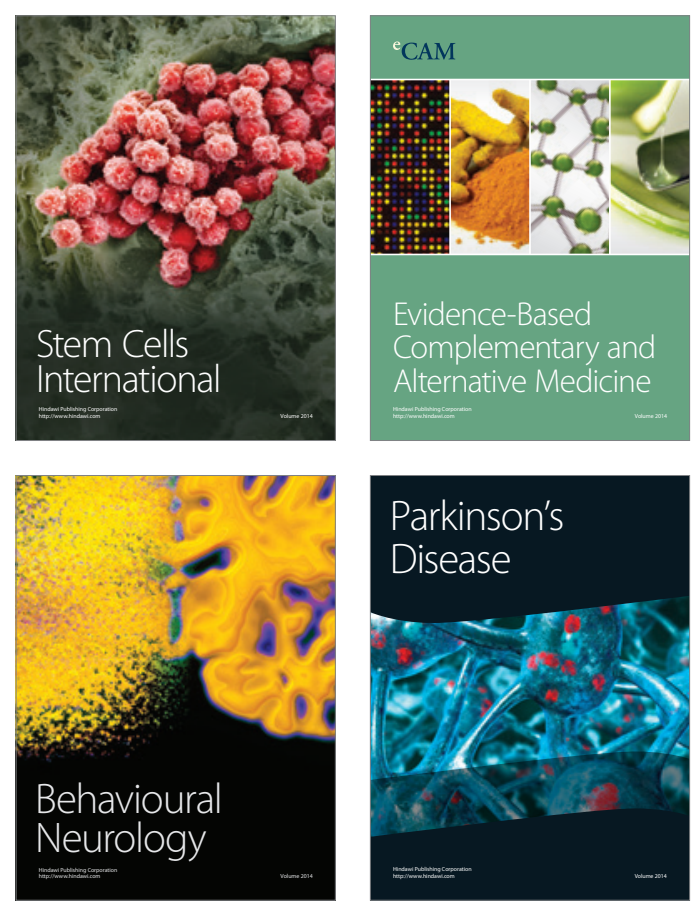

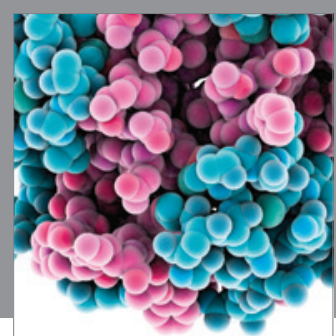

Journal of
Diabetes Research

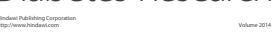

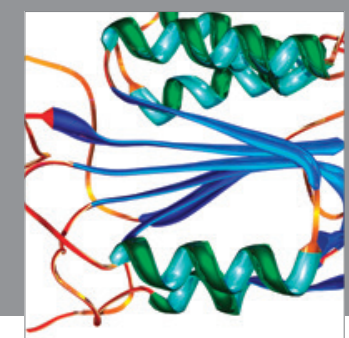

Disease Markers
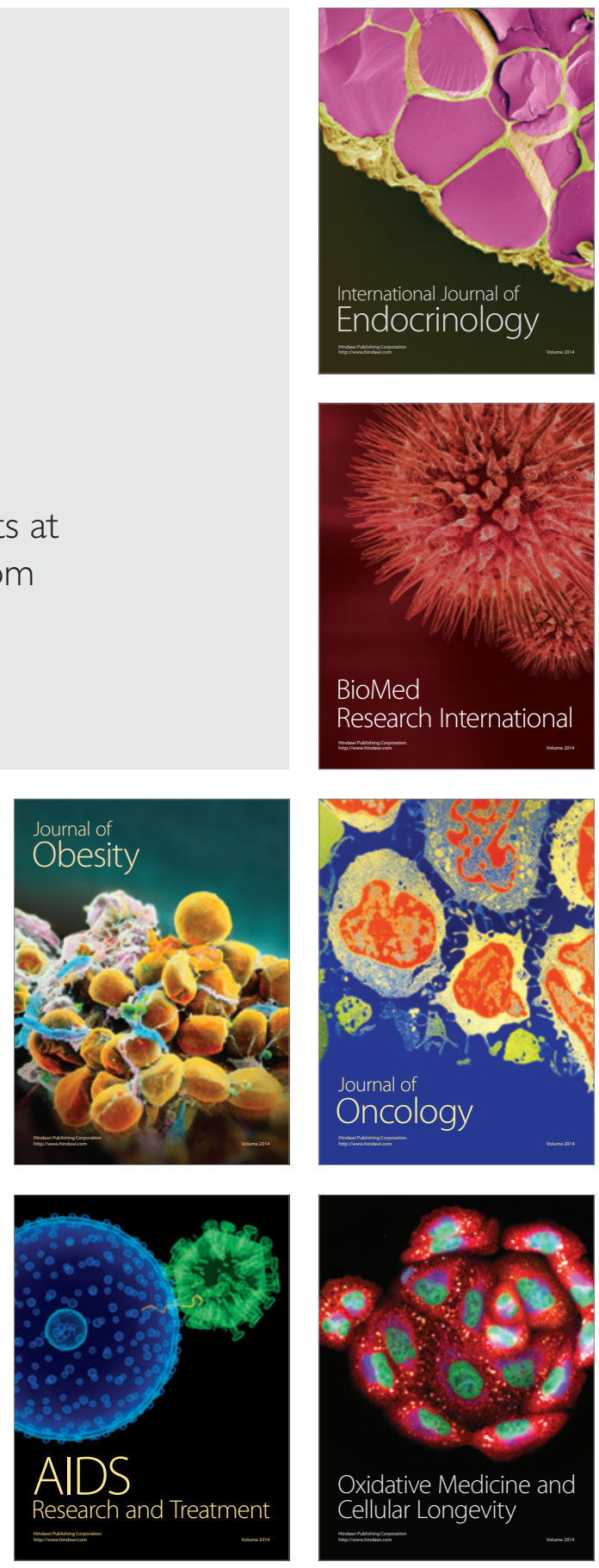